\title{
APPROXIMATION SCHEMES FOR MONOTONE SYSTEMS OF NONLINEAR SECOND ORDER PARTIAL DIFFERENTIAL EQUATIONS: CONVERGENCE RESULT AND ERROR ESTIMATE
}

\author{
ARIEla Briani, FABIO CAMILli AND HaSNAA ZidANI
}

Abstract. We consider approximation schemes for monotone systems of fully nonlinear second order partial differential equations. We first prove a general convergence result for monotone, consistent and regular schemes. This result is a generalization to the well known framework of Barles-Souganidis, in the case of scalar nonlinear equation. Our second main result provides the convergence rate of approximation schemes for weakly coupled systems of Hamilton-JacobiBellman equations. Examples including finite difference schemes and Semi-Lagrangian schemes are discussed.

Mathematics subject classification (2010): 35J45, 49L25, 65N15.

Keywords and phrases: monotone systems, viscosity solution, approximation scheme, error estimate.

\section{REFERENCES}

[1] G. BARLES AND E. R. JAKOBSEN, On the convergence rate of approximation schemes for HamiltonJacobi-Bellman equations, M2AN Math. Model. Numer. Anal., 36 (2002), 33-54.

[2] G. BARLES AND E. R. JAKOBSEN, Error bounds for monotone approximation schemes for HamiltonJacobi-Bellman equations, SIAM J. Numer. Anal., 43 (2005), 540-558.

[3] G. BARLES AND E. R. JAKOBSEN, Error bounds for monotone approximation schemes for parabolic Hamilton-Jacobi-Bellman equations, Math. Comp., 76 (2007), 1861-1893.

[4] G. BARles AND P. E. SOUGANIDIS, Convergence of approximation schemes for fully nonlinear second order equations, Asymptotic Anal., 4 (1991), 271-283.

[5] M. Bladt, E. MÉndez And P. Padilla, Pricing derivatives incorporating structural market changes and in time correlation, Stoch. Models, 24 (2008), 164-183.

[6] J. F. Bonnans, S. MARoso AND H. ZIDANI, Error bounds for stochastic differential games: the adverse stopping case, IMA J. Numer. Anal., 26 (2006), 188-212.

[7] J. F. Bonnans, S. MARoso AND H. ZidAni, Error estimates for a stochastic impulse control problem, Applied Mathematics and Optimization, 55 (2007), 327-357.

[8] J. F. BONNANS AND H. ZIDANI, Consistency of generalized finite difference schemes for the stochastic HJB equation, SIAM J. Numerical Analysis, 41 (2003), 1008-1021.

[9] J. F. Bonnans, E. Ottenwaelter And H.Zidani, A fast algorithm for two-dimensional HJB equation of stochastic control, M2AN Math. Model. Numer. Anal., 38 (2004), 723-735.

[10] L. A. CAFFARElli, P.E. Souganidis, A rate of convergence for monotone finite difference approximations to fully nonlinear, uniformly elliptic PDEs, Comm. Pure Appl. Math., 61 (2008), 1-17.

[11] F. CAMilli AND M. FAlCONE, An approximation scheme for the optimal control of diffusion processes, RAIRO Modél. Math. Anal. Numér., 29 (1995), 97-122.

[12] F. CAmilli And E. R. JAKOBSEn, A finite element like scheme for integro-partial differential Hamilton-Jacobi-Bellman equations, SIAM J. Numer. Anal., 47 (2009), 2407-2431.

[13] H. ENGLER AND S. LENHART, Viscosity solutions for weakly coupled systems of Hamilton-Jacobi equations, Proc. London Math. Soc., 63 (1991), 212-240.

[14] A. FAHIM, N. TOUZI AND X. WARIN, A probabilistic numerical scheme for fully nonlinear parabolic PDEs, preprint 2009. 
[15] M. K. Ghosh, A. Arapostathis And S. I. Marcus, Optimal control of switching diffusions with application to flexible manufacturing systems, SIAM J. Control Optim., 31 (1993), 1183-1204.

[16] R. L. V. GonZÁLEZ AND E. RofmAn, On unbounded solutions of Bellman's equation associated with optimal switching control problems with state constraints, Appl. Math. Optim., 31 (1995), 1-17.

[17] H. IsHII, Perron's method for monotone systems of second-order elliptic PDEs, Diff. and Int. Eq., 5 (1992), 1-24.

[18] H. ISHII, On the equivalence of two notions of weak solutions, viscosity solutions and distribution solutions, Funkcialaj Ekvacioj, 38 (1995), 101-120.

[19] H. ISHII AND S.KoIKE, Viscosity solutions for monotone systems of second-order elliptic PDEs, Comm. Partial Differential Equations, 16 (1991), 1095-1128.

[20] E. R. JAKOBSEN, On error bounds for approximation schemes for non-convex degenerate elliptic equations, BIT, 44 (2004), 269-285.

[21] N. V. KRYLOV, Approximating value functions for controlled degenerate diffusion processes by using piece-wise constant policies, Electron. J. Probab., 4 (1999), 1-19.

[22] N. V. KRYLOV, On the rate of convergence of finite-difference approximations for Bellmans equations with variable coefficients, Probab. Theory Ralat. Fields, 117 (2000), 116.

[23] N. V. KRYLOV, The rate of convergence of finite-difference approximations for Bellman equations with Lipschitz coefficients, Applied Math. and Optimization, 52 (2005), 365-399.

[24] H. J. KUSHNER AND P. G. DUPUIS, Numerical methods for stochastic control problems in continuous time, Vol 24 of Applications of Mathematics, Springer, NewYork, 2001 (Second edition).

[25] R. Munos And H. ZIDAni, Consistency of a simple multidimensional scheme for HJB equations, C. R. Acad. Sci. Paris, Ser. I, 340 (2005), 499-502.

[26] N. YAMADA, Viscosity solutions for a system of elliptic inequalities with bilateral obstacle, Funkcial. Ekvac., 30 (1987), 417-425. 